\title{
BMJ Open Prescription for antibiotics at drug shops and strategies to improve quality of care and patient safety: a cross-sectional survey in the private sector in Uganda
}

Anthony K Mbonye, ${ }^{1,2}$ Esther Buregyeya, ${ }^{3}$ Elizeus Rutebemberwa, ${ }^{3}$ Siân E Clarke, ${ }^{4}$ Sham Lal, ${ }^{4}$ Kristian S Hansen, ${ }^{5}$ Pascal Magnussen, ${ }^{6}$ Philip LaRussa ${ }^{7}$

To cite: Mbonye AK, Buregyeya $\mathrm{E}$,

Rutebemberwa $\mathrm{E}$, et al. Prescription for antibiotics at drug shops and strategies to improve quality of care and patient safety: a crosssectional survey in the private sector in Uganda. BMJ Open 2016:6:e010632

doi:10.1136/bmjopen-2015010632

- Prepublication history and additional material is available. To view please visit the journal (http://dx.doi.org/ 10.1136/bmjopen-2015010632).

Received 25 November 2015 Accepted 26 January 2016

CrossMark

For numbered affiliations see end of article.

Correspondence to Dr Anthony K Mbonye; akmbonye@yahoo.com

\section{ABSTRACT}

Objectives: The main objective of this study was to assess practices of antibiotic prescription at registered drug shops with a focus on upper respiratory tract infections among children in order to provide data for policy discussions aimed at improving quality of care and patient safety in the private health sector in Uganda.

Methods: A survey was conducted within 57 parishes from August to October 2014 in Mukono District, Uganda. Data was captured on the following variables: drug shop characteristics, training of staff in management of pneumonia, availability of guidelines and basic equipment, available antibiotics, knowledge on treatment of pneumonia in children aged $<5$ years. The main study outcome was the proportion of private health facilities prescribing an antibiotic.

Results: A total of 170 registered drug shops were surveyed between August and October 2014. The majority of drug shops, $93.5 \%$ were prescribing antibiotics, especially amoxicillin and trimethoprimsulfamethoxazole (septrin). The professional qualification of a provider was significantly associated with this practice, $p=0.04$; where lower cadre staff (nursing assistants and enrolled nurses)

overprescribed antibiotics. A third, $29.4 \%$ of drug shop providers reported that antibiotics were the first-line treatment for children with diarrhoea; yet the standard guideline is to give oral rehydration salts and zinc tablets. Only few providers, $8.2 \%$, had training on antibiotics, with $10.6 \%$ on pneumonia case management. Further to this, $7.1 \%$ drug shops had WHO-Integrated Management of Childhood IIIness guidelines, and a negligible proportion $(<1 \%)$ had respiratory timers and baby weighing scales. Although the majority of providers, $82.4 \%$, knew severe signs and symptoms of pneumonia, few, $17.6 \%$, knew that amoxicillin was the first-line drug for treatment of pneumonia in children according to the guidelines. Conclusions: There is urgent need to regulate drug shop practices of prescribing and selling antibiotics, for the safety of patients seeking care at these outlets.

\section{Strengths and limitations of this study}

- This study is based on a large cross-sectional survey of drug shops in Uganda.

- It aims at assessing practices of antibiotic prescription at drug shops, with a focus on the use of antibiotics for the treatment of respiratory tract infections, in order to inform future study designs of interventions to improve quality of care in this sector.

- This is an important aspect of a public-private partnership to improve the health of people seeking care at such outlets.

- However, we were unable to observe prescription practices; and our results are limited to provider reports. Similarly, there is poor record keeping at drug shops; and this limits analysis of prescription of antibiotics to sick patients.

\section{BACKGROUND}

Self-medication with antimicrobial agents is widely reported among patients globally. Some of the factors associated with selfmedication include poor regulation of prescription practices, limited knowledge of drug effects, high costs of seeking care at health facilities, advice from friends, previous experience, waiting time and long distances to the health facilities. ${ }^{1-5}$

Currently, there is a dangerous spread of resistance against antibiotics, and there is an urgent need to combat this spread. The spread is mainly among low-income countries and poor communities with inadequate access to the medicines, who cannot afford the high prices. It has been recommended that countries need to strengthen health systems to control the spread of antimicrobial resistance. ${ }^{6}$ 
A study in Uganda found that the majority of clients, $57 \%$, visiting two pharmacies in the capital city, practiced self-medication with drugs, including antibiotics. ${ }^{7}$ Another study on antibiotic sale at retail chemist shops in Nairobi showed that about $64 \%$ of chemists sold antibiotics without prescriptions. Most shops sold underdoses (below the recommend dose); and the practice was more common in periurban areas than in the city centre. The study further showed that antibiotics were prescribed for $31 \%$ of the mothers/guardians. Of the antibiotics dispensed, 38\% were not prescribed by clinicians. $^{8}$

Similarly, a study in Tanzania showed that a high proportion of medicines sold in pharmacies were dispensed without a prescription; and these were requested by the client or recommended by the dispenser. When dispensing medicines, dispensers seldom gave dosage instructions; and when they did, the instructions were often not consistent with guidelines. ${ }^{9}$

It has also been shown that a high proportion of clients seeking management of coughs/colds, or for diarrhoea, from private pharmacies, receive antibiotics. The study concluded that interventions that build the capacity of dispensers, improve the rational use of antibiotics and the management of diarrhoea in private pharmacies in Tanzania were necessary to provide quality services to the population that relies heavily on the private sector. ${ }^{10}$

In Uganda, it has also been shown that appropriate prescribing for acute respiratory infections (ARI) and malaria was poor in both public and private sectors. Prescribing antibiotics for ARI was nearly universal in both public and private sectors, with some prescriptions containing up to three antibiotics. Newer and more expensive antibiotics were more commonly prescribed in the private sector. ${ }^{11}$ A study in India recently showed that prescription errors were most commonly observed at private hospitals, and antibiotics were commonly prescribed in the private sector, and recommended a strict policy for good prescribing practice to promote rational use of drugs.

Currently, there is little known on prescription and sale of antibiotics in drug shops in Uganda where most people with illnesses seek care. The main objective of this study, therefore, was to assess practices of antibiotic prescription with a focus on respiratory tract infections among children, at drug shops, in order to inform future study designs for interventions to improve quality of care in this sector.

\section{METHODS}

\section{Study setting}

The study was conducted in Mukono, central Uganda. The total population of the district is 565700 , with an annual growth rate of $2.3 \%$, and predominantly consists of the Baganda ethnic group. ${ }^{12}$ The majority of the population, $88 \%$, lives in the rural areas. In the central region where Mukono District is located, there is high prevalence of childhood illnesses. For example, a total of $42.4 \%$ of children aged $<5$ years had fever, $9.4 \%$ had symptoms of acute respiratory tract infections, and $22.3 \%$ had diarrhoea in the 2 weeks prior to the survey, according to the Demographic and Health Survey in Uganda in 2011. ${ }^{13}$

\section{Study design}

A survey was conducted within 57 geographical areas (parishes) in Mukono District, central Uganda. A list of all parishes in Mukono District was obtained from the Uganda Bureau of Statistics. Parishes were selected based on the following criteria: (1) contained a health centre II, the lowest public health facility where early treatment is sought; (2) contained more than 200 households to ensure a sufficient number of patients visiting the facilities and (3) contained at least one registered drug shop, pharmacy or private clinic. All registered drugs shops in the 57 parishes (that met the above criteria); and consented to the study, were included in the survey. In total, 170 drug shops were surveyed from August to October 2014. A few, three, did not consent to the study because the providers were not available.

Data was collected using a structured questionnaire targeting one provider who was found on duty in each selected drug shop. In Uganda, a drug shop is required to meet minimum standards for registration, including ownership and operation of the business, by a qualified health worker, and premises suitable for storage of drugs; they are subject to periodic inspection by the District Assistant Drug Inspector (DADI), with a license renewable annually for a fee. A registered drug shop is licensed to sell non-prescription drugs, including antimalarial drugs but not antibiotics or injectable drugs. ${ }^{14}$

The standard guideline for treating diarrhoea in children in Uganda is as follows: A child who has diarrhoea for $<14$ days, with no blood in stool, and with no other danger sign, should be given oral rehydration salts (ORS) solution, and a zinc supplement, while a child aged 2 months to 5 years with upper respiratory infection must have an antibiotic. A child who has cough and rapid breathing for less than 21 days with no danger signs, should be treated with amoxicillin. ${ }^{15}$

\section{Data sources}

A structured questionnaire targeting drug shops was used to collect data on: provider characteristics, previous training received, type of drugs stocked, knowledge on treatment and prevention of common childhood illnesses (see online supplementary file). Interviewers underwent refresher training on research techniques and study procedures for 5 days, and participated in the pretesting and revision of the questionnaire tools before actual fieldwork. Questionnaires were administered in English language since all the providers had a working knowledge of English. Site supervisors monitored and supervised all aspects of data. The main study outcome 
was the proportion of drug shop providers prescribing and selling an antibiotic 2 weeks prior to the survey.

\section{Sample size calculation}

Sample size calculation was based on the proportion of drug shops prescribing and selling antibiotics, estimated at $40 \%$. In order to estimate the proportion with a $\pm 11 \%$ absolute precision, at a power of $80 \%$ and $5 \%$ level of significance (two-sided), a minimum of 156 drug shops with $10 \%$ non-participation were required.

\section{Data analyses}

Data was entered and verified using Microsoft Access 2007 (Microsoft Inc, Redmond, Washington, USA) and analysed using STATA V.11.0 (STATA Corporation, College Station, Texas, USA). Univariate analyses were performed to get proportions on key variables; and bivariate analyses were used to assess factors associated with prescribing and selling of antibiotics. Since prescription and selling of antibiotics in all the facilities was $>95 \%$, we could not do any multivariable analyses.

Written informed consent was sought prior to the interviews. Data was securely locked and accessible only to the investigators.

\section{RESULTS}

\section{Characteristics of drug shops}

A total of 170 drug shops participated in the study; the response rate was $98 \%$. The reason for non-response was absence of the provider in the selected drug shop. The majority, $75.6 \%$, were registered by the National Drug Authority (NDA). Few drug shops, 15.9\%, had stock cards (these are cards that record the number and type of drugs stored/dispensed); and $53.3 \%$ were injecting patients; a practice that they are not authorised to do (table 1).

\section{Staff characteristics}

The staff were predominantly females, $87.7 \%$, and half of them, $52.9 \%$, had attained secondary education, while

\begin{tabular}{lc}
$\begin{array}{l}\text { Table } 1 \text { Characteristics of registered drug shops in } \\
\text { Mukono District }\end{array}$ & $\begin{array}{l}\text { Registered } \\
\text { drug shops } \\
\mathbf{N}=\mathbf{1 7 0}\end{array}$ \\
\hline & $29(23.6 \%)$ \\
Characteristics & $93(75.6 \%)$ \\
\hline Where drug shop is registered & $36(21.2 \%)$ \\
$\quad$ District (receipt seen) & $27(15.9 \%)$ \\
$\quad$ National Drug Authority (license seen) & $90(53.3 \%)$ \\
Drug shops with a patient register & $8(12 \%)$ \\
Drug shops with stock control cards & \\
Drug shops injecting patients & $89(52.4 \%)$ \\
Average number of injections per week & \\
(mean, SD) & \\
Facilities with a dustbin for disposal of used & 89 \\
syringes, needles and other sharp materials &
\end{tabular}

the other half, $47.1 \%$ had tertiary education (table 2). Few staff, $30.6 \%$, at drug shops, were enrolled nurses/ midwives. The study explored training related to childhood illnesses, and only a few staff, 9.5\%, had training on pneumonia management using Integrated Management of Childhood Illness (IMCI) guidelines. Less than one half had training in malaria using IMCI guidelines; $28.2 \%$ and $46.6 \%$ had been trained on rapid diagnostic tests (RDTs) for malaria (table 2).

Availability of guidelines, basic equipment and supplies at drug shops

Few drug shops, $7.1 \%$ had IMCI guidelines, and a negligible proportion had an RDT for malaria diagnosis, while $17.9 \%$ had malaria treatment guidelines (table 3 ). The majority, $54.1 \%$ had disposable syringes and needles, and $52.4 \%$ had containers for disposal of waste products (table 3 ).

\section{Prescription and selling antibiotics at drug shops}

The majority of drug shops sold antibiotics to their clients 2 weeks prior to the survey as follows: amoxicillin, $89.5 \%$, trimethoprim-sulfamethoxazole (septrin), $95.6 \%$, tetracycline, $51.9 \%$, gentamicin, $41.3 \%$, penicillin, $56.9 \%$. Although the majority of staff, $82.4 \%$, knew the signs and symptoms of severe pneumonia, few, $17.6 \%$,

\begin{tabular}{|c|c|}
\hline Staff characteristics & $\begin{array}{l}\text { Registered } \\
\text { drug shops } \\
\mathrm{N}=170\end{array}$ \\
\hline \multicolumn{2}{|l|}{ Sex } \\
\hline Male & $21(12.4)$ \\
\hline Female & $149(87.7)$ \\
\hline \multicolumn{2}{|l|}{ Education } \\
\hline Secondary & $90(52.9)$ \\
\hline Tertiary & $80(47.1)$ \\
\hline University & $0(0.0)$ \\
\hline \multicolumn{2}{|l|}{ Highest level of professional training attained } \\
\hline Nursing aide & $11(6.5)$ \\
\hline Enrolled nurse/midwife & $52(30.6)$ \\
\hline Registered nurse/midwife & $6(3.5)$ \\
\hline Clinical officer & $4(2.4)$ \\
\hline Doctor & $0(0.0)$ \\
\hline \multicolumn{2}{|l|}{ Training in malaria case management } \\
\hline Artemisinin combination therapy (ACT) & $73(42.9)$ \\
\hline $\begin{array}{l}\text { Integrated Management of Childhood } \\
\text { IIIness (IMCI) guidelines }{ }^{*}\end{array}$ & $48(28.2)$ \\
\hline Rapid diagnostic tests (RDTs) & 79 (46.5) \\
\hline Microscopy & $11(6.5)$ \\
\hline \multicolumn{2}{|l|}{ Training in pneumonia case management } \\
\hline Antibiotics & $14(8.2)$ \\
\hline IMCI guidelines & $16(9.4)$ \\
\hline \multicolumn{2}{|l|}{ Training in diarrhoea case management } \\
\hline Microscopy & $10(5.9)$ \\
\hline $\mathrm{IMCl}$ quidelines & $42(24.7)$ \\
\hline RDT & $26(15.3)$ \\
\hline
\end{tabular}


Table 3 Availability of guidelines, basic equipment and supplies to treat sick children at drug shops in Mukono District

\begin{tabular}{lc}
\hline $\begin{array}{l}\text { Availability of guidelines, basic } \\
\text { equipment and supplies }\end{array}$ & $\begin{array}{l}\text { Number (\%) } \\
\text { of drug shops } \\
(\mathbf{N}=170)\end{array}$ \\
\hline $\begin{array}{l}\text { Drug shops with malaria treatment } \\
\text { guidelines }\end{array}$ & $30(17.9)$ \\
$\begin{array}{l}\text { Integrated Management of Childhood } \\
\text { Illness guidelines }\end{array}$ & $12(7.1)$ \\
$\begin{array}{l}\text { Thermometer } \\
\text { Rapid diagnostic tests for malaria } \\
\text { diagnosis }\end{array}$ & $160(94.1)$ \\
$\begin{array}{l}\text { Drug shops with a functioning laboratory } \\
\text { Drug shops with a functioning } \\
\text { microscope }\end{array}$ & $44(43.8)$ \\
$\begin{array}{l}\text { Proportion of drug shops with disposable } \\
\text { syringes and needles }\end{array}$ & $92(54.1)$ \\
$\begin{array}{l}\text { Drug shops with a baby weighing scale } \\
\text { Drug shops with a respiratory timer }\end{array}$ & $1(0.6)$ \\
\hline
\end{tabular}

knew that amoxicillin was the first-line drug for treating pneumonia among children, according to the guidelines (table 4). In addition, $30 \%$ of drug shops reported that antibiotics were the first-line treatment for children with diarrhoea. The standard guideline for treating uncomplicated diarrhoea in Uganda is to give ORS and zinc tablets.

Factors associated with prescription of antibiotics, in general, were assessed; the lower cadre (nursing aide, nursing assistant and enrolled nurses) were more likely to prescribe and sell antibiotics compared to the higher cadre professionals, $\mathrm{p}=0.04$, (table 4 ).

\section{DISCUSSION}

Our findings show that the majority of drug shops were prescribing and selling antibiotics, especially amoxicillin and trimethoprim-sulfamethoxazole (septrin). Despite this, few of them had training on antibiotics and pneumonia case management, while a negligible proportion had IMCI guidelines, respiratory timers and baby weighing scales. Surprisingly, although most staff knew signs and symptoms of severe pneumonia among children, few knew that amoxicillin was the first-line drug for treatment of pneumonia, according to the guidelines.

Drug shops in Uganda are authorised to sell class-C drugs (over the counter) that do not require prescription. However, they are not authorised to sell antibiotics and injectable drugs. ${ }^{15}$ Thus, the present findings highlight the importance of compliance with regulations by drug shops, and this has implications for the safety of patients seeking care at these outlets. The indiscriminate prescription and sale of antibiotics has potential to increase drug pressure and subsequent antimicrobial resistance. An earlier study in Uganda also found that of
Table 4 Prescription of antibiotics, knowledge of first-line drugs and severe signs/symptoms for pneumonia in Mukono District

\begin{tabular}{|c|c|}
\hline & $\begin{array}{l}\text { Number }(\%) \\
\text { of drug shops } \\
(\mathrm{N}=170)\end{array}$ \\
\hline $\begin{array}{l}\text { Drug shops prescribing and selling } \\
\text { antibiotics }\end{array}$ & $159(93.5)$ \\
\hline \multicolumn{2}{|l|}{ Specific antibiotic } \\
\hline Amoxicillin & $143(89.4)$ \\
\hline Septrin & $153(95.6)$ \\
\hline Tetracycline & $83(51.9)$ \\
\hline Gentamicin & $66(41.3)$ \\
\hline Penicillin & $75(46.9)$ \\
\hline $\begin{array}{l}\text { Knowledge that amoxicillin is the first-line } \\
\text { treatment for pneumonia in children }\end{array}$ & $29(17.6)$ \\
\hline $\begin{array}{l}\text { Knowledge that rapid breathing, difficulty } \\
\text { in breathing, cough, chest in-drawing, are } \\
\text { symptoms/signs for severe pneumonia }\end{array}$ & $140(82.4)$ \\
\hline $\begin{array}{l}\text { Proportion of drug shops prescribing } \\
\text { antibiotics as the first-line treatment for } \\
\text { diarrhoea }\end{array}$ & $50(29.4 \%)$ \\
\hline \multicolumn{2}{|c|}{ Factors associated with antibiotic prescription } \\
\hline Urban/rural location & $\mathrm{p}=0.8$ \\
\hline A drug shop having a patient register & $p=0.4$ \\
\hline $\begin{array}{l}\text { Number of children with fever aged } \\
\text { less than } 5 \text { years visiting the drug shop }\end{array}$ & $p=0.8$ \\
\hline $\begin{array}{l}\text { Number of children with cough aged } \\
\text { less than } 5 \text { years visiting the drug shop }\end{array}$ & $p=0.9$ \\
\hline $\begin{array}{l}\text { Number of children with diarrhoea } \\
\text { aged less than } 5 \text { years visiting the drug } \\
\text { shop }\end{array}$ & $p=0.8$ \\
\hline Profession qualification of the provider & $p=0.04$ \\
\hline $\begin{array}{l}\text { Attended a short course on } \\
\text { management of pneumonia }\end{array}$ & $p=0.5$ \\
\hline
\end{tabular}

the patients who sought treatment at private clinics within 1 week of onset of symptoms, only $7 \%$ of them were properly managed. ${ }^{16-22}$ Similar findings have been documented in Ghana where a high proportion, $70 \%$ of the respondents, practiced self-medication, and the most common antibiotic used was amoxicillin. ${ }^{23}$

It is noted that the majority of drug shops (53.3\%), were injecting patients probably with gentamicin and penicillin, to treat other bacterial infections like skin infections and urethritis or urinary tract infections.

The following strategies to improve quality of care and safety of patients are proposed; drug shops are not allowed to sell antibiotics according to the law. Yet, almost all drug shops surveyed did sell antibiotics. It would be relevant in future research to investigate where and how the system fails to enforce the law properly.

The current policy in Uganda is to support publicprivate partnerships to promote health, and the findings of this study will contribute to the current initiatives to improve quality of care in the private health sector. Thus, there is need to disseminate results to district 
authorities, programme managers and policymakers, to initiate discussions on modalities of regulating drug shop practices. There is urgent need to strengthen the NDA and the DADI, to provide inspection and regulation by increasing funding and personnel. Our study results could also be helpful to initiate discussion on how to revise the current policy in order to allow training and supervision of drug shops to allow prescription of antibiotics and improve patient safety.

The limitation of this study is that we relied on provider reports, and we could not ascertain the accuracy of these reports. Similarly, we did not directly observe the practice of antibiotic dispensing and what signs and symptoms patients present with. Similarly, the memory recall of events surrounding the prescription of antibiotics at drug shops within 2 weeks, limits the accuracy of these data. This, however, required an in-depth study that required direct observations and records reviews that was beyond the scope of this study, and we recommend it for further research.

This study focused on prescription practices of antibiotics, and we did not explore the disease conditions for which the antibiotics were prescribed. In addition, due to poor record keeping at drug shops, we could not analyse trends of antibiotic prescription to sick patients who visit drug shops. It is possible, that antibiotics were prescribed for diseases like urinary tract infections, skin conditions, and other upper respiratory conditions. We intend to explore this in a follow-up study. Nonetheless, the survey covered a large number of drug shops, and the results can be generalised to most parts of Uganda.

Following this study, we have designed an intervention, a cluster randomised study (NCT02450630; registered with ClinicalTrials.gov; on 20 May 2015), to assess the effect of strengthening treatment and referral of sick children from the private health sector in Uganda. The key elements of the intervention are to train drug shop providers to use RDTs for malaria, and ICCM algorithms to treat and refer sick children; to hold regular meetings between the private and public sectors; and to improve community awareness on the importance of timely health-seeking and referral of sick children. We hope that the evaluation of this intervention will provide useful data on antibiotic prescriptions, especially to malaria-negative patients presenting at these outlets.

\footnotetext{
Author affiliations

${ }^{1}$ Ministry of Health, Directorate of Clinical and Community Services, Kampala, Uganda

${ }^{2}$ Department of Community \& Behavioural Sciences, School of Public Health, Makerere University, Kampala, Uganda

${ }^{3}$ Department of Disease Control \& Environmental Health, School of Public Health, Makerere University, Kampala, Uganda

${ }^{4}$ Department of Disease Control, London School of Hygiene and Tropical Medicine, London, UK

${ }^{5}$ Department of Global Health and Development, London School of Hygiene and Tropical Medicine, London, UK

${ }^{6}$ Institute for International Health, Immunology and Microbiology, Centre for Medical Parasitology and Institute for Veterinary disease Biology, Faculty of
}

Health and Medical Sciences, University of Copenhagen, Copenhagen, Denmark

${ }^{7}$ College of Physicians \& Surgeons, Columbia University, New York, USA

Acknowledgements The authors are grateful to Mr Steven Kalake (field supervisor), and the data management staff; the district health officer Mukono district Dr Elly Tumushabe and Mr Hakim Kalungi, the Mukono District health educator for supporting the study.

Contributors AKM conceived the study. All authors (EB, ER, SEC, SL, $\mathrm{KSH}, \mathrm{PM}, \mathrm{PL}$ ) participated in the design of the study and supervision of data collection. AKM wrote the first draft of the manuscript and all authors (EB, ER, SEC, SL, KSH, PM, PL) contributed to, read and approved the final manuscript.

Funding The study was supported by the Partnership for Enhanced Engagement in Research (PEER) programme administered by the National Academy of Sciences (NAS) and funded by the US Agency for International Development (USAID) in partnership with the US National Institutes of Health $(\mathrm{NIH})$.

Competing interests None declared.

\section{Patient consent Obtained.}

Ethics approval Ethical approval for the research was granted from review boards at Makerere University School of Public Health and the Uganda National Council of Science and Technology (Ref: ss 3529).

Provenance and peer review Not commissioned; externally peer reviewed.

Data sharing statement Additional data can be accessed via the Dryad data repository at http://datadryad.org/ with the doi:10.5061/dryad.9c87t.

Open Access This is an Open Access article distributed in accordance with the Creative Commons Attribution Non Commercial (CC BY-NC 4.0) license, which permits others to distribute, remix, adapt, build upon this work noncommercially, and license their derivative works on different terms, provided the original work is properly cited and the use is non-commercial. See: http:// creativecommons.org/licenses/by-nc/4.0/

\section{REFERENCES}

1. Chioro A, Coll-Seck AM, Høie B, et al. Antimicrobial resistance: a priority for global health action. Bull World Health Organ 2015;93:439.

2. Ocan M, Bwanga F, Bbosa GS, et al. Patterns and predictors of self-medication in northern Uganda. PLOS ONE 2014; 9:e92323.

3. van der Geest S. Self-care and the informal sale of drugs in South Cameroon. Soc Sci Med 1987;25:293-305.

4. Mbonye AK, Neema S, Magnussen P. Malaria in pregnancy, risk perceptions and care seeking practices among adolescents in Mukono district Uganda. Int $J$ Adolesc Med Health 2006;18: 561-73.

5. Mbonye AK. Prevalence of childhood illnesses and care-seeking practices in rural Uganda. ScientificWorld Journal 2003;3:721-30.

6. Mbonye AK, Sentongo M, Mukasa GK, et al. Newborn survival in Uganda: a decade of change and future implications; Uganda Decade of Change and Future Implications Analysis Group. Health Policy Plan 2012;27(Suppl 3):iii104-17.

7. Anyama N, Adome RO. Community pharmaceutical care: an 8-month critical review of two pharmacies in Kampala. Afr Health Sci 2003;3:87-93.

8. Indalo AA. Antibiotic sale behaviour in Nairobi: a contributing factor to antimicrobial drug resistance. East Afr Med J 1997;74 171-3

9. Nsimba SE. Assessing the performance, practices and roles of drug sellers/dispensers and mothers'/guardians' behaviour for common childhood conditions in Kibaha district, Tanzania. Trop Doct 2007;37:197-201.

10. Kagashe GA, Minzi O, Matowe L. An assessment of dispensing practices in private pharmacies in Dar-es-Salaam, Tanzania. Int J Pharm Pract 2011;19:30-5.

11. Ogwal-Okeng JW, Obua C, Waako $P$, et al. A comparison of prescribing practices between public and private sector physicians in Uganda. East Afr Med J 2004;(Suppl):S12-16. 
12. Uganda Bureau of Statistics. The statistical abstract. Kampala, Uganda: Uganda Bureau of Statistics, 2000.

13. Uganda Bureaux of Statistics. Uganda demographic and health survey. Kampala, Uganda: Uganda Bureaux of Statistics, 2011.

14. Ministry of Health. Health sector strategic plan III. Kampala, Uganda: Ministry of Health, 2010.

15. Ministry of Health. Uganda clinical guidelines. Kampala, Uganda: Ministry of Health, 2012.

16. Minzi O, Manyilizu V. Application of basic pharmacology and dispensing practice of antibiotics in accredited drug-dispensing outlets in Tanzania. Drug Health Patient Saf 2013;5:5-11.

17. Shelat PR, Kumbar SK. Analysis of out door patients' prescriptions according to World Health Organization (WHO) prescribing indicators among private hospitals in Western India. J Clin Diagn Res 2015;9:FC01-4.

18. Jacobs B, Whitworth J, Kambugu F, et al. Sexually transmitted disease management in Uganda's private-for-profit formal and informal sector and compliance with treatment. Sex Transm Dis 2004;31:650-4.
19. Fernandes $P$. The global challenge of new classes of antibacterial agents: an industry perspective. Curr Opin Pharmacol 2015;24:7-11.

20. Nouér SA, Nucci M, Anaissie E. Tackling antibiotic resistance in febrile neutropenia: current challenges with and recommendations for managing infections with resistant Gram-negative organisms. Expert Rev Hematol 2015;8: 647-58.

21. van Oosten M, Hahn M, Crane LM, et al. Targeted imaging of bacterial infections: advances, hurdles and hopes. FEMS Microbiol Rev 2015;39:892-916.

22. Perez F, Villegas MV. The role of surveillance systems in confronting the global crisis of antibiotic-resistant bacteria. Curr Opin Infect Dis 2015;28:375-83.

23. Donkor ES, Tetteh-Quarcoo PB, Nartey P, et al. Self-medication practices with antibiotics among tertiary level students in Accra, Ghana: a cross-sectional study. Int J Environ Res Public Health 2012;9:3519-29. 